\title{
Rainfall threshold definition using an entropy decision approach and radar data
}

\author{
V. Montesarchio, E. Ridolfi, F. Russo, and F. Napolitano \\ Dipartimento di Ingegneria Civile, Edile e Ambientale, Sapienza Università di Roma, Rome, Italy \\ Received: 19 June 2010 - Revised: 16 June 2011 - Accepted: 20 June 2011 - Published: 27 July 2011
}

\begin{abstract}
Flash flood events are floods characterised by a very rapid response of basins to storms, often resulting in loss of life and property damage. Due to the specific spacetime scale of this type of flood, the lead time available for triggering civil protection measures is typically short. Rainfall threshold values specify the amount of precipitation for a given duration that generates a critical discharge in a given river cross section. If the threshold values are exceeded, it can produce a critical situation in river sites exposed to alluvial risk. It is therefore possible to directly compare the observed or forecasted precipitation with critical reference values, without running online real-time forecasting systems. The focus of this study is the Mignone River basin, located in Central Italy. The critical rainfall threshold values are evaluated by minimising a utility function based on the informative entropy concept and by using a simulation approach based on radar data. The study concludes with a system performance analysis, in terms of correctly issued warnings, false alarms and missed alarms.
\end{abstract}

\section{Introduction}

Classical real-time flood forecasting systems generally must run hydrological models in real-time. The time required for the model to run can be greater than the lead time available for issuing alerts in basins subject to flash flooding. A flood warning system based on a comparison of observed or forecasted precipitation and critical rainfall values could provide decision-makers with relatively simple, clear, and immediate messages. Rainfall thresholds specify the amount of precipitation for a given duration that generates a critical discharge in a given river cross section. If the thresholds are exceeded,

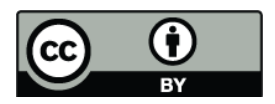

Correspondence to: V. Montesarchio (valeria.montesarchio@uniroma1.it) it can produce a critical situation in river sites exposed to alluvial risk, triggering prevention operations and emergency system alerts (Georgakakos, 1995).

In this work the critical rainfall thresholds for the Mignone River cross section are defined using an entropy-based decision approach and a simulation approach based on radar data, in order to establish rainfall warning values for critical flood events. First, an overview of the entropy concept is given. Second, the methodology for rainfall thresholds estimation is presented and applied to the case study of the Mignone River. Finally, the reliability of rainfall thresholds is evaluated and results are discussed.

\section{The entropy concept}

The entropy concept was introduced by Clausius in 1864 (from ancient Greek en, "inside", and troph, "change") to explain heat behaviour at different temperatures. The entropy of a system is given by the sum of the entropy of each part of the system, so that for $m$ subsystems, $H$ is

$$
H=\sum_{i=1}^{m} H_{i}=\sum_{i=1}^{m} k \ln p_{i}
$$

where $H_{i}$ is the entropy of each subsystem $i, p_{i}$ is the probability of being in the ith state and $k$ is a positive constant. Assuming $k=1$ and the base of logarithm as 2, the measure of entropy is in bit (as in this work). The most probable distribution of the energy in a system is one for which the entropy of the whole system would be equal to its maximum value:

$H=\sum_{i=1}^{m} k \ln p_{i}=\max$

Heuristic entropy can be interpreted as a measure of the uncertainty about the occurrence of a certain event (Papoulis, 1991). The probability $P(A)$, for example, of an event $A$,

Published by Copernicus Publications on behalf of the European Geosciences Union. 
can be defined as the measure of the uncertainty about the occurrence or not-occurrence of $A$. If $A_{i}$ events are a partition of the event $U$, so that each event is incompatible with others $\left(A_{i} A_{j}=\emptyset\right.$ for $\left.i \neq j\right)$, and the union of all the events is $U$ itself $\left(U=A_{1} \cup A_{2} \cup \ldots A_{n}\right)$, then the measure of the uncertainty of $U$ is $H(U)$ and it is the entropy of the partition of $U$. The functional $H(U)$ was derived from a number of postulates, such as:

1. $H(U)$ is a continuous function of $p_{i}=P\left(A_{i}\right)$;

2. if $p_{1}=\ldots=p_{N}=1 / N$, then $H(U)$ is an increasing function of $N$;

3. if a new partition $B$ is formed by subdividing one of the sets of $U$, then $H(B)>H(U)$,

it can be shown that the sum:

$H(U)=-p_{1} \log _{2} p_{1}-\ldots-p_{N} \log _{2} p_{N}$

satisfies the postulates and is unique within a constant factor.

\subsection{Discrete random variable (RV) type}

Suppose that $x$ is a discrete type of RV taking the value $x_{i}$ with probability

$P\left\{X=x_{i}\right\}=p_{i}$.

The events $\left\{X=x_{i}\right\}$ are mutually exclusive and their union is the certain event; hence they form a partition. This partition will be denoted by $U_{x}$.

The entropy $H(X)$ of a discrete-type RV $X$ is the entropy $H\left(U_{x}\right)$ of its partition $U_{x}$ (Papoulis, 1991):

$H(X)=H\left(U_{X}\right)=E\left[-\log _{2} p(X)\right]=-\sum_{i} p_{i} \log _{2} p_{i}$.

\subsection{Continuous random variable (RV) type}

The entropy of a continuous-type RV cannot be so defined because the events $\left\{X=x_{i}\right\}$ do not form a partition. The entropy of a continuous type RV $X$ is by definition the integral (Papoulis, 1991):

$H(X)=-\int_{-\infty}^{\infty} f(x) \log _{2} f(x) d x$

The integration extends only over the region where $f(x) \neq 0$ because $f(x) \ln f(x)=0$ if $f(x)=0$.

\section{Flood rainfall thresholds}

Generally, rainfall thresholds identify precipitation critical values, which could be used in the context of landslides and debris flow hazard forecasting (Neary and Swift, 1987; Annunziati et al., 1999; Crosta and Frattini, 2000), as well as in flood forecasting or warning (Carpenter et al., 1999; Mancini et al., 2002; Georgakakos, 2006; Martina et al., 2006). In the context of flood warning, when critical values are exceeded, flooding is expected. Rainfall thresholds specify the amount of precipitation for a given duration that generates a critical discharge in a given cross section.

There is a long tradition of rainfall threshold-based methodologies, although different approaches have been adopted. The Flash Flood Guidance method (FFG) (Mogil et al., 1978) was developed by the US National Weather Service (NWS) for flash flood warning. FFG is based on the effective depth of rain of a given duration, taken as uniform in space and time, necessary to cause minor flooding (e.g., 2 yr return time flow) at the outlet of the considered basin. If the FFG is surpassed by rainfall amounts, then flooding in the basin is considered likely to occur. FFG values are computed as the flow causing flooding divided by the catchment area times the Unit Hydrograph's (Snyder's or Geomorphologic) peak value for any specified duration. GIS support is used to determine the main characteristics of the basin, and regionalization values are provided to extend the methodology to other locations (Carpenter et al., 1999).

The key advantage of FFG is that it is possible to issue warnings without the need to run entire hydrometeorological forecasting chains. The limitations of FFG are in the assumptions of spatially/temporally uniform rainfall and linear responses (i.e., that affect the size of the basins), and the use of regional relationships to make inferences about ungauged locations. FFG performance in ungauged basins is poor (Norbiato et al., 2008), because the hydrological model parameters cannot be calibrated (Bloeschl, 2005) and it is more difficult to estimate critical discharge values (Ntelekos et al., 2006).

A different approach was proposed by Mancini et al. (2002). Threshold values are estimated with an eventbased rainfall-runoff model, which iteratively searches for the rainfall amount that could produce a critical discharge or water stage. As input of the rainfall runoff model, synthetic hyetographs with different shapes and durations are used. This is a deterministic approach and has been used in previous work (e.g., Montesarchio et al., 2009); it will be further discussed in Sect. 3.1.

Lastly, a utility function approach couples rainfall and discharge in a probabilistic way (Martina et al., 2006). The rainfall incorporates the dependence between the cumulated rainfall volume for the storm duration and the possible consequences on the water level or discharge in a river section as perceived by the stakeholders. The thresholds therefore correspond to the minimum expected value of an opportunely chosen Bayesian cost utility function. This approach is used as a probabilistic approach in the present work and will be further discussed in Sect. 3.2. Moreover, this approach is extended by employing an entropy-based decision function to overcome the subjectivity implied in the Bayesian approach (Sect. 3.2.2). 


\subsection{Deterministic approach for rainfall threshold evaluation}

The deterministic approach needs an opportunely calibrated rainfall runoff model to simulate basin response to storms. The inverse hydrologic problem is iteratively solved to identify, for a given duration $d$, the cumulative rainfall that corresponds to the critical discharge. The identification of the critical section is usually based on the flooding history of the river and its hydraulic geometry. When this information is not available, the critical section can be identified as the outlet of the basin, where all of the upstream contributions converge.

Given the hydraulic geometry and the marked critical water stage, the critical discharge is estimated by using the stage-discharge curve (Rosso, 2002). When the discharge data are unavailable and a hydraulic simulation cannot be carried out, a regional model can be applied (e.g., the index discharge method; Darlymple, 1960) in order to identify the critical discharge. This method is based on statistical regionalization and allows for the replacement of time with space and the use of a set of hydrometric observations from a homogeneous area to replace the lack of hydrometric data in the critical section. Given a certain return period, the maximum discharge for the critical section is calculated as the product of two terms: a scaling factor which is characteristic of the site, and a dimensionless growth factor which is characteristic of the homogenous region.

In the gauged sections it is clearly possible to calculate the discharge index directly using the arithmetic mean of the available data. For the ungauged sections, indirect methods (e.g., Brath et al., 2001) must be used instead. With this approach, a critical rainfall threshold is obtained which no longer refers to the critical discharge but to the different return periods (i.e., 2, 5, 10, 20, 50, $100 \mathrm{yr}$ ). A description of the procedures which must be carried out in order to evaluate the critical rainfall thresholds in different situations is reported in Montesarchio et al. (2009). The critical reference discharge could be reached and surpassed for different space-time configurations of rainfall fields. To simplify, cumulative precipitation $(P)$ can be evaluated globally over the entire basin, after a time $(d)$ from the beginning of a thunderstorm. Rainfall thresholds are generally a function of the critical cross-section characteristics, but also of the boundary conditions (e.g., soil imbibition condition at the beginning of the event) and the type and temporal evolution of the rain event. These dependencies can be summarised using the AMC (Antecedent Moisture Condition) index (SCS, 1971, 1986) and standard hyetograph (Rosso, 2002).

Given hyetograph, rain duration $(d)$ and initial soil imbibition condition based on the AMC index, the critical depth can be investigated. Independent simulations can be performed for all combinations of rainfall durations (3, 6, 12 and $24 \mathrm{~h})$, hyetographs and AMC classes. The rainfall thresholds are iteratively identified by trial and error until the critical discharge value is reached.

\subsection{Probabilistic approach for rainfall threshold evalu- ation}

To evaluate the threshold values corresponding to the minimum expected value of an opportunely chosen function, the joint cumulative distribution of cumulated rainfall and the corresponding peak discharge must be defined. Also, when a probabilistic approach is used, the soil moisture conditions affect the threshold values. Using a hydrological simulation approach, the peak discharge was evaluated for each AMC class.

\subsubsection{Bayesian approach}

The "convenience" concept is introduced in relation to damage perception, and is measured by a Bayesian utility function that also includes immeasurable damages derived by missed alarms. The utility function is dependent on the critical discharge value (Martina et al., 2006), such that:

$U\left(q, v \mid V_{\mathrm{T}}, T\right)=\left\{\begin{array}{l}\frac{a}{1+b e^{-c\left(q-Q^{*}\right)}} \quad \text { if } v \leq V_{\mathrm{T}} \\ C_{0}+\frac{a^{\prime}}{1+b^{\prime} e^{-c^{\prime}\left(q-Q^{*}\right)}} \quad \text { if } v \geq V_{\mathrm{T}},\end{array}\right.$

where: $q$ is the discharge value; $Q^{*}$ is the critical discharge value for the river critical cross section; $v$ is the cumulated rainfall value; $V_{\mathrm{T}}$ is the critical threshold value; $T$ is the storm duration $(3,6,12,24 \mathrm{~h})$; and $a, b, c$ and $C_{0}, a^{\prime}, b^{\prime}$, $c^{\prime}$ are proper parameters.

The utility function $U\left(q, v \mid V_{\mathrm{T}}, T\right)$ for values of $v<V_{\mathrm{T}}$ expresses damage perception if the alert is missed. There are negligible costs if the effective discharge $q$ is lower than $Q^{*}$, while the cost increases rapidly if $q$ is higher than $Q^{*}$. For values of $v>V_{\mathrm{T}}$, the function expresses damage perception if the alert is issued. Costs are initially higher in the latter scenario than in the no-alarm case because of the operative costs associated with triggering civil protection measures; however, the costs grow slowly if $q$ is higher than $Q^{*}$.

The parameters $a, b, c$ and $C_{0}, a^{\prime}, b^{\prime}, c^{\prime}$ change with the importance given to the possible combination of actions (i.e., issuing an alert or not) and actual process (i.e., the critical discharge is surpassed or not).

Regarding the liability of the decision-maker in determining whether or not to issue an alarm, three cases can be distinguished (FLOODsite, 2008): the "real" case, the "risk prone" case and the "risk averse" case. A different set of parameters ( $a, b, c$ and $C_{0}, a^{\prime}, b^{\prime}, c^{\prime}$ ) corresponds to each case, resulting in different costs. The parameters of the utility function are summarized in Table 1.

In the "risk averse" case, since the costs associated with a false alarm are negligible, issuing false alarms is preferred over risking the possibility of a missed alarm. The costs of failing to issue an alarm can grow rapidly in a real emergency, and the difference in maximum cost between alarm 
Table 1. Utility function parameters (FLOODsite, 2008).

\begin{tabular}{lccccccccc}
\hline & \multicolumn{3}{c}{ alarm } & & \multicolumn{4}{c}{ no alarm } \\
\cline { 2 - 3 } \cline { 7 - 9 } parameters $(€)$ & $a$ & $b$ & $c$ & & $a^{\prime}$ & $b^{\prime}$ & $c^{\prime}$ & Co \\
\hline "Risk averse" case & $10 \times 10^{6}$ & 2 & 0.020 & & $3 \times 10^{6}$ & 60 & 0.030 & $7 \times 10^{3}$ \\
"Risk prone" case & $10 \times 10^{6}$ & 500 & 0.023 & & $7 \times 10^{6}$ & 1000 & 0.027 & $15 \times 10^{3}$ \\
"Real" case & $10 \times 10^{6}$ & 200 & 0.025 & & $5 \times 10^{6}$ & 800 & 0.030 & $10 \times 10^{3}$ \\
\hline
\end{tabular}

and no-alarm scenarios is great. In the "risk prone" case some costs for flood events are considered more acceptable than false alarm costs. Areas of low economic value can be affected by low intensity floods, while more valuable areas (economically and socially) will be affected for a higher return period. False alarm costs are higher than in the previous case, because resources must be employed when the alarm is issued. In the "real" case, the real experiences of decision-makers in issuing alarms are evaluated. The cost of a false alarm is evaluated operatively (e.g., 50 employees and their equipment). The missed alarm cost grows when the discharge exceeds the project reference value for structural protection measures. The functions corresponding to each risk case are shown in Fig. 1.

The most convenient threshold value $V_{\mathrm{T}}$ is identified (for each duration $T=3,6,12,24$ hours) by minimising the expected utility cost function:

$$
\begin{aligned}
& V_{\mathrm{T}}=\operatorname{Min}_{V_{\mathrm{T}}}\left\langle E\left\{U\left(q, v \mid V_{\mathrm{T}}, T\right)\right\}\right\rangle= \\
& =\operatorname{Min}_{V_{\mathrm{T}}}\left\langle\int_{0}^{+\infty} \int_{0}^{+\infty} U\left(q, v \mid V_{\mathrm{T}}, T\right) f(q, v \mid T) d q d v\right\rangle,
\end{aligned}
$$

where $f(q, v \mid T)$ is the joint distribution of cumulated rainfall volume and peak discharge (as determined in Sect. 4.3) and $U\left(q, v \mid V_{\mathrm{T}} T\right)$ is the utility function.

\subsubsection{Utility-entropy function}

The definition of measure of risk based on the expected values of utility and entropy (Yang and Qiu, 2005) is defined on the basis of the classical decision model under risk. Three parts are defined: the state space $\Theta=\{\theta\}$, the action space $A=\{a\}$, and the payoff function $X=X(a, \theta)$, defined for $A \times Q$. The decision model is therefore $G=$ $(Q, A, u)$, where $u=u(X)$ is the decision maker's utility function. Suppose that at least two actions exist in action space, so the decision-maker's utility function is nonnegative and the mean $a \in A\{|E[u(X(a, \theta))]|\}$ exists. When the mean $a \in A\{|E[u(X(a, \theta))]|\}$ is nonzero, the measure of risk when taking an action $a$ is defined as:
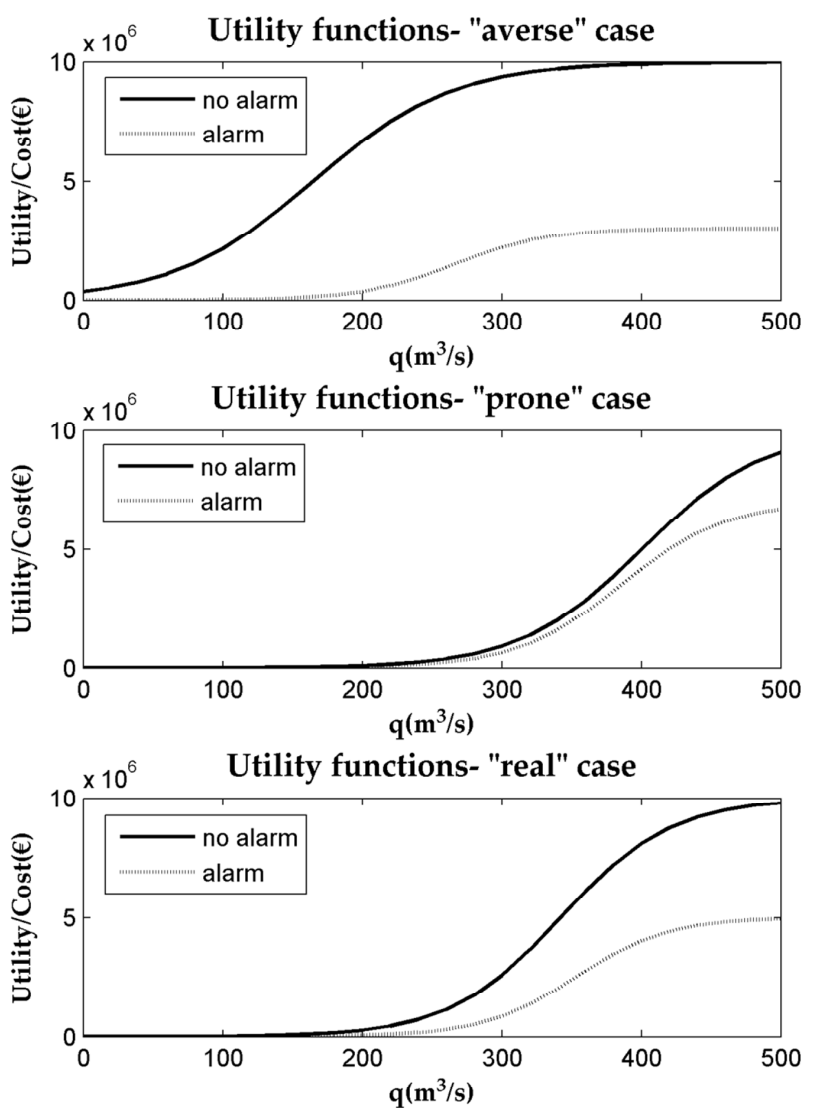

Fig. 1. Utility functions for different risk cases. The dotted line represents the function if the alert is issued, the solid line if not.

$$
\begin{aligned}
R(a)= & \lambda H_{a}(\theta)+(1-\lambda) E[(u(X(a, \theta))] \\
& / \operatorname{mean}_{a \in A}\{|E[u(X(a, \theta))]|\},
\end{aligned}
$$

where $\lambda$ is a constant $(0<\lambda<1), R(a)$ denotes the risk of taking an action $a$, and $H_{a}(\theta)$ represents the entropy of the distribution of the corresponding state. When $\operatorname{mean}_{a \in A}\{|E[u(X(a, \theta))]|\}=0$, then for any action $a \in A \rightarrow$ $E[u(X(a, \theta))]=0$. In this case $R(a)=H_{a}(\theta)$.

This measure of risk is defined as the expected value of the utility entropy (EU-E). The entropy is the objective measure 
of the uncertainty of the state of nature $\theta$. The constant $\lambda$ is defined as the "tradeoff coefficient" and it reflects a tradeoff between the subjective utility of a decision-maker's action and the objective uncertainty of its corresponding state. When the decision-maker wants the expected utility to have a greater effect, then $\lambda=0$; when the decision-maker wants an expected utility to have a smaller effect, then $\lambda=1$.

The EU-E measure is relative. It depends on the expected function of entropy and utility and on the expected value of every action. The tradeoff coefficient provides a balance of these factors that can be used for the decision-maker's subjective valuation. The expected value of utility reflects the subjective preference, while the entropy represents the objective uncertainty about a decision.

The utility function is introduced according to Bayesian decisional theory and represents the cost of flood damages in cases where an alarm was either issued or missed during a flood event (Martina et al., 2006), as shown in Eq. (7). The parameters of the general decision model are explained in Sect. 4.5.2.

\section{Case study}

\subsection{Basin characteristics}

The Mignone River in Italy originates at the confluence between the Scatenato, Coriglione and Biscione ditches, at $633 \mathrm{~m}$ a.s.1. The total length is $62 \mathrm{~km}$, from the Sabatini Mountains (northeast to Lake Bracciano) to the Tyrrhenian Sea (between Tarquinia and Civitavecchia).

Near Rota (from the hydrographical left), the Mignone River receives the Verginese ditch tributary and, near Monte Romano (from hydrographical right) it receives the Vesca Stream. The overall contribution is scarce and the hydraulic behaviour is variable, which is typical of a torrential regimen. The basin area is characterized by hilly zones with some relief with steep slopes corresponding to the water-engraved valley. The total area is about $560 \mathrm{~km}^{2}$, with an average elevation of $233 \mathrm{~m}$ a.s.1. The basin has an essentially horizontal development, bounded in the North by the Cimini Mountains and hill relief towards the sea (near Tarquinia), and in the South by the Sabatini and Tolfa Mountains. Geologically, the Mignone River basin is characterized by volcanic rocks $(25 \%)$ in the mountainous areas, while further downstream there are sands and conglomerates (14\%), clay (9\%), and anthropogenic rocks $(2 \%)$, but mainly flysch (41\%), as well as, of course, alluvial deposits along the river $(9 \%)$. There are no carbonates. The Mignone River area was influenced by the explosive activity of the Vulsini, Vico Lake and Cimino complex, alternating layers of clay and marl. The Mignone River therefore has a low permeability which implies that the flows range from very low to very high values, depending on the rain regimen.

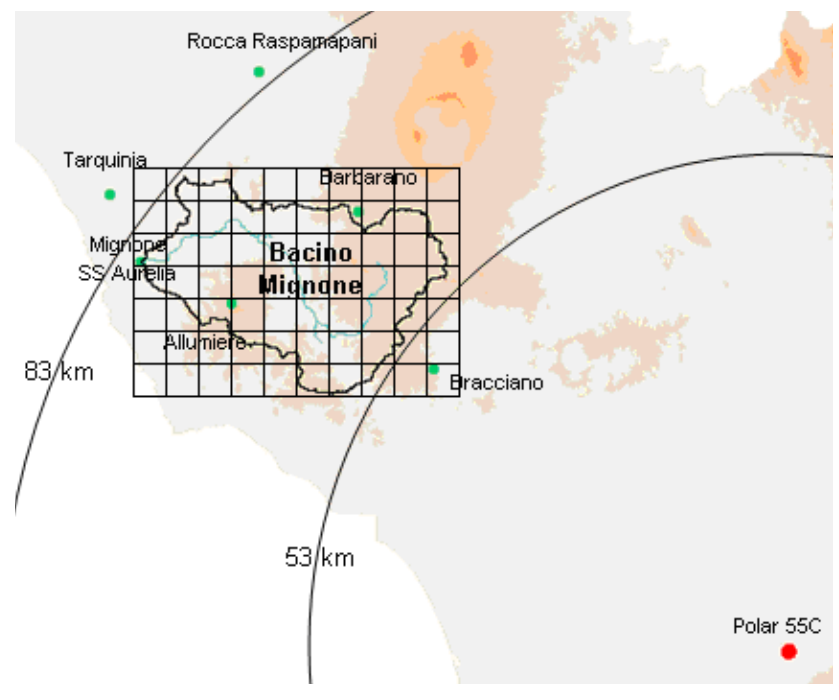

Fig. 2. Study area and radar position. The red dot in the lower right-hand corner represents the position of the Polar 55C radar. A $2 \mathrm{~km} \times 2 \mathrm{~km}$ grid was overlaid over the map of entire basin, located in the Northeast with respect to the radar. The green dots represents the available rain gauge stations in the study area.

\subsection{Data set}

Information about historical Mignone River flood events is available on the Sistema Informativo Catastrofi Idrogeologiche (SICI) of the Consiglio Nazionale delle RicercheGruppo Nazionale per la Difesa dalle Catastrofi Idrogeologiche CNR-GNDCI website. The preliminary historicaldocumentary analysis was used to identify the critical hydraulic cross-section with the monitored cross-section "S.S. Aurelia" (drainage area $440 \mathrm{~km}^{2}$ ), near which the Mignone River overflowed three times during the last century (8 November 1934, 27 December 1959, 16 November 1962). Given cross-section geometry and the stage-discharge curve used by the authorities, it was determined that the critical reference discharge $Q^{*}=131.0 \mathrm{~m}^{3} \mathrm{~s}^{-1}$ (Montesarchio et al., 2009). To the critical reference discharge corresponds a return period of $1.25 \mathrm{yr}$, evaluated with a partial duration series method. It means that reaching critical conditions in Mignone River basin is quite common, and having a skilled warning system available would prevent damage and loss.

\subsubsection{Hydrometric and pluviometric data}

Hydrometric and pluviometric data (from 1999 until 2008) were used both for marginal and joint distribution fitting. Hydrometric data were used also to perform the calibration and verification of the rainfall-runoff model, which is based on radar data. A summary of flood events affecting the Mignone River basin from 1999 to 2007 can be found in Montesarchio et al. (2009). 

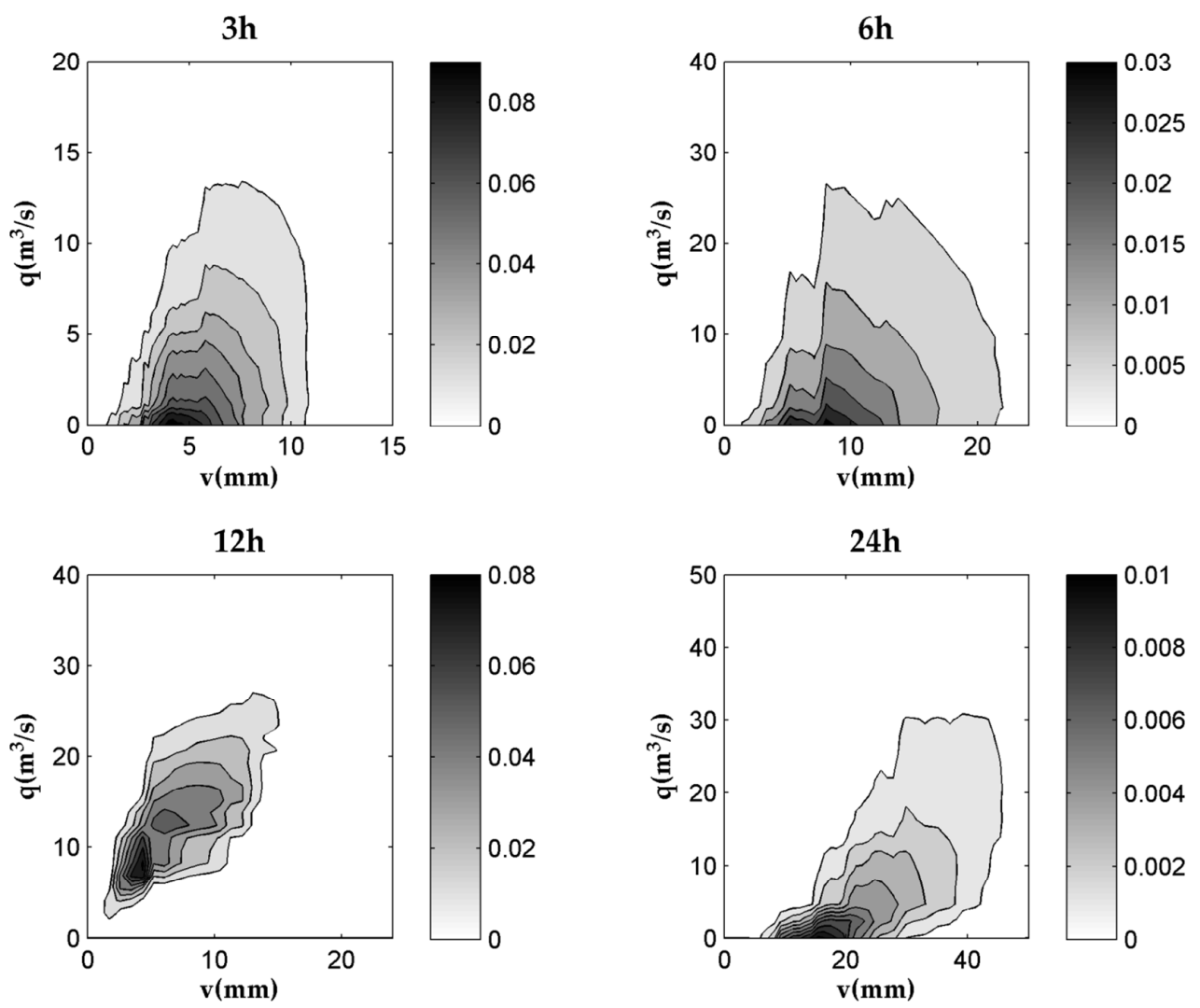

Fig. 3. Joint probabilities distributions for rainfall depth-cumulated rainfall $(3,6,12,24 \mathrm{~h})$, for soil AMCIII condition.

Hydrometric and pluviometric data of the years 2009 and 2010 are used to add a short validation period to test the efficiency of rainfall thresholds based warning system.

\subsubsection{Radar data}

The Polar 55C radar is located $15 \mathrm{~km}$ southeast of Rome, Italy, in the Tor-Vergata research centre. The Polar 55C is a C-band Doppler weather radar with polarization agility and a $0.9^{\circ}$ beam width. The radar is capable of transmitting and receiving horizontally and vertically polarized signals on alternate pulses, which allows the reflectivity factor $\left(Z_{\mathrm{h}}\right)$, the differential reflectivity $\left(Z_{\mathrm{dr}}\right)$, and the differential phase shift $\left(\Phi_{\mathrm{dp}}\right)$ to be measured.

Radar measurements are obtained by averaging 64 pulses with a range-bin resolution of $75 \mathrm{~m}$ covering a $120 \mathrm{~km}$ radius from the radar site. The temporal resolution is $5 \mathrm{~min}$. To remove the spurious returns from the data, an algorithm based on polarimetry is applied (Lombardo et al., 2006a).

The following $Z-R$ relation was obtained for the Cband radar using a nonlinear regression analysis (Russo et al., 2005):

$R=7.27 \times 10^{-2} Z_{h}^{0.62}$,

where $Z_{h}$ is the reflectivity factor $\left(\mathrm{mm}^{6} \mathrm{~m}^{-3}\right)$ and $R$ is the rainfall rate $\left(\mathrm{mm} \mathrm{h}^{-1}\right)$.
Radar data provide fine space-time resolution rainfall, useful for hazard nowcasting (Lombardo et al., 2006b, 2009), flood forecasting (Russo et al., 2006; Montesarchio et al., 2009) and sewer system monitoring (Giulianelli et al., 2006). On the other hand, despite continuous technological progress, the available instruments used to measure rainfall across several spatio-temporal scales remain inaccurate (Villarini et al., 2007), implying inaccuracies in rainfall estimates.

In this work we are assuming that uncertainties in radarderived precipitation estimates are negligible, even if it is well known that these estimates are affected by sources of uncertainty (Wilson and Brandes, 1979; Krajewski and Smith, 2002; Habib et al., 2004; Germann et al., 2006; Ciach et al., 2007; Villarini and Krajewski, 2010a). However, in these studies operative radar networks are examined. The Polar $55 \mathrm{C}$ is a research radar, with higher measuring performance than operative network. So the radar-rainfall estimates are considered error-free (see also Ntelekos et al. (2006) for a similar application).

After the transformation from polar to Cartesian coordinates was performed, a $2 \mathrm{~km} \times 2 \mathrm{~km}$ grid was overlaid over the map of entire basin (Fig. 2). For each temporal interval the values of the rainfall rate were obtained at each pixel, and thus it was possible to calculate the cumulative rainfall 
Table 2. Marginal distributions parameters of observed cumulated values $v$ and corresponding peak discharge $q$, sorted by duration.

\begin{tabular}{|c|c|c|c|c|}
\hline Duration & $\begin{array}{l}\text { AMC } \\
\text { Class }\end{array}$ & $\begin{array}{l}\text { Data } \\
\text { series }\end{array}$ & Distribution & $\begin{array}{l}\text { Parameters } \\
\text { values }\end{array}$ \\
\hline $3 \mathrm{~h}$ & III & $\begin{array}{l}v(\mathrm{~mm}) \\
q\left(\mathrm{~m}^{3} \mathrm{~s}^{-1}\right) \\
v(\mathrm{~mm}) \\
q\left(\mathrm{~m}^{3} \mathrm{~s}^{-1}\right) \\
v\left(\mathrm{~mm}^{-1}\right) \\
q\left(\mathrm{~m}^{3} \mathrm{~s}^{-1}\right)\end{array}$ & $\begin{array}{l}\text { exponential } \\
\text { Frechet } \\
\text { exponential } \\
\text { Frechet } \\
\text { exponential } \\
\text { Frechet }\end{array}$ & $\begin{array}{l}\lambda=0.29 \\
\alpha=3.03 ; \varepsilon=1.36 \\
\lambda=0.29 \\
\alpha=-3.15 ; \varepsilon=1.52 \\
\lambda=0.29 \\
\alpha=-3.27 ; \varepsilon=1.70\end{array}$ \\
\hline $6 \mathrm{~h}$ & III & $\begin{array}{l}v(\mathrm{~mm}) \\
q\left(\mathrm{~m}^{3} \mathrm{~s}^{-1}\right) \\
v(\mathrm{~mm}) \\
q\left(\mathrm{~m}^{3} \mathrm{~s}^{-1}\right) \\
v\left(\mathrm{~mm}^{-1}\right) \\
q\left(\mathrm{~m}^{3} \mathrm{~s}^{-1}\right)\end{array}$ & $\begin{array}{l}\text { exponential } \\
\text { Frechet } \\
\text { exponential } \\
\text { Frechet } \\
\text { exponential } \\
\text { Frechet }\end{array}$ & $\begin{array}{l}1=0.17 \\
\alpha=1.87 ; \varepsilon=1.80 \\
\lambda=0.17 \\
\alpha=1.77 ; \varepsilon=2.00 \\
\lambda=0.17 \\
\alpha=1.70 ; \varepsilon=2.22\end{array}$ \\
\hline $12 \mathrm{~h}$ & III & $\begin{array}{l}v(\mathrm{~mm}) \\
q\left(\mathrm{~m}^{3} \mathrm{~s}^{-1}\right) \\
v\left(\mathrm{~mm}^{3}\right) \\
q\left(\mathrm{~m}^{3} \mathrm{~s}^{-1}\right) \\
v\left(\mathrm{~mm}^{2}\right) \\
q\left(\mathrm{~m}^{3} \mathrm{~s}^{-1}\right)\end{array}$ & $\begin{array}{l}\text { exponential } \\
\text { log-normal } \\
\text { exponential } \\
\text { log-normal } \\
\text { exponential } \\
\text { log-normal }\end{array}$ & $\begin{array}{l}\lambda=0.11 \\
\mu=2.68 ; \sigma=0.77 \\
\lambda=0.11 \\
\mu=2.33 ; \sigma=0.72 \\
\lambda=0.11 \\
\mu=2.56 ; \sigma=0.76\end{array}$ \\
\hline $24 \mathrm{~h}$ & III & $\begin{array}{l}v(\mathrm{~mm}) \\
q\left(\mathrm{~m}^{3} \mathrm{~s}^{-1}\right) \\
v\left(\mathrm{~mm}^{-1}\right. \\
q\left(\mathrm{~m}^{3} \mathrm{~s}^{-1}\right) \\
v\left(\mathrm{~mm}^{-1}\right. \\
q\left(\mathrm{~m}^{3} \mathrm{~s}^{-1}\right)\end{array}$ & $\begin{array}{l}\text { exponential } \\
\text { log-normal } \\
\text { exponential } \\
\text { log-normal } \\
\text { exponential } \\
\text { log-normal }\end{array}$ & $\begin{array}{l}\lambda=0.04 \\
\mu=3.19 ; \sigma=0.77 \\
\lambda=0.04 \\
\mu=3.54 ; \sigma=0.83 \\
\lambda=0.04 \\
\mu=3.88 ; \sigma=0.86\end{array}$ \\
\hline
\end{tabular}

by radar with a temporal resolution of $30 \mathrm{~min}$. The radar data have only been available since 2008; as such, a total of five events were used to calibrate the model in the saturated soil condition (i.e., AMCIII). More events, not used in calibration phase, are used also to test the warning procedures.

\subsection{Fitting marginal and joint distribution}

Given the dependence of rainfall threshold values on soil moisture conditions, it would have been optimal to initially subdivide the available data based on AMC condition and then further subdivide by duration. However, subdividing the data according to AMC classes created very short data series, thereby increasing the uncertainty of the statistical inference process. Therefore, the series were classified firstly according to their duration, and then used in a hydrological simulation framework to obtain also different AMC series. The distributions fitting the cumulated rainfall $v$ and the peak discharge $q$ and their parameters are summarized in Table 2.

The marginal probability distributions were determined in order to obtain the joint distributions; the marginals were processed through the Normal Quantile Transformation (NQT) (Kelly and Krzystofowicz, 1997) and by a metaGaussian relationship:

$$
\begin{aligned}
& h(q, v)=\frac{f(q) g(v)}{\sqrt{1-\gamma^{2}}} \\
& \exp \left\{-\frac{\gamma}{2\left(1-\gamma^{2}\right)}\left[\gamma\left[Q^{-1}(F(q))\right]^{2}\right.\right. \\
& -2\left[Q^{-1}(F(q))\right]\left[Q^{-1}(G(v)]+\gamma\left[Q^{-1}(G(v)]^{2}\right]\right\}
\end{aligned}
$$

where $Z_{i}=Q^{-1}\left(F\left(q_{i}\right)\right)$ and $W_{i}=Q^{-1}\left(G\left(v_{i}\right)\right)$ are the inverse of the standard normal distribution functions derived from the parameters of the marginal series, $f(q)$ and $g(v)$ are the marginal density functions and $\gamma$ is related to the Pearson correlation coefficient $\rho$ between $Z$ and $W$ :

$\rho=(6 / \pi) \arcsin (\gamma / 2)$.

For each duration:

$h(q, v)=h(q, v \mid T)$,

where $T$ is $3,6,12$ or $24 \mathrm{~h}$. In Fig. 3 the calculated joint distributions are shown for the AMCIII soil condition. 
Table 3. Parameters values for models calibrated with radar data.

\begin{tabular}{lccc}
\hline AMCIII Class & Subbasin & & Subbasin \\
\hline & S.S. Aurelia & & Rota \\
\cline { 2 - 2 } Initial Abstraction Ratio & 1 & & 1 \\
Potential Retention Scale Factor & 0.35 & & 0.35 \\
Time of Concentration (h) & 6.11 & & 3.55 \\
Storage Coefficient (h) & 8.28 & & 3.08 \\
Lag (min) & 192.82 & & - \\
\hline
\end{tabular}

\subsection{Simulation model}

A rainfall-runoff model was implemented, through which the behavior of the basin was simulated. The calibrated model was used to solve the inverse hydrological problem in the critical section.

The rainfall-runoff model used in this work is semidistributed, so that the spatial variability of the physical processes can be taken into account. Even though the critical rainfall threshold is expressed in terms of cumulative rainfall, it is important to assess the response of the basin in case of a distributed spatial input, as the critical situation can also be caused by localized rainfall.

In order to outline the rainfall-runoff transformation in both sub-basins, a modified Clark model was employed (Peters and Easton, 1996; Kull and Feldmann, 1998); this permits a semi-distributed approach to be used, which takes into account the spatial variability of the physical processes. In order to outline the hydrological losses, a SCS-CN grid model (SCS, 1971, 1986) and Lag model were used to outline the propagation of the full flood wave (Pilgrim and Cordery, 1993).

Figure 4 shows the calibration and verification of the hydrological model for the AMCIII class. Table 3 summarizes the values of the model's parameters. In order to evaluate the performance of the model, the following two indicators were considered: the Root Mean Squared Error (RMSE) and the efficiency coefficient (CE). Their values are $59.46 \mathrm{~m}^{3} \mathrm{~s}^{-1}$ and 0.24 , respectively.

\subsection{Rainfall thresholds evaluation}

\subsubsection{Bayesian approach}

The Bayesian approach is described in Martina et al. (2006). Here, only graphical and numerical results related to the Mignone River case study are reported (Fig. 5, Table 4). For each AMC condition, three curves were obtained, corresponding to the various risk cases. Clearly, higher saturation will result in lower corresponding threshold values.
9-14 December 2008 Calibration AMC 3 RADAR

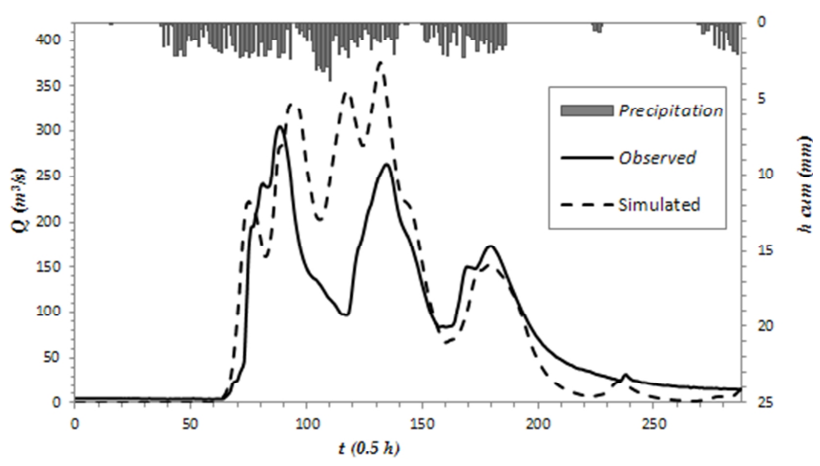

14-18 December 2008 Validation AMC 3 RADAR

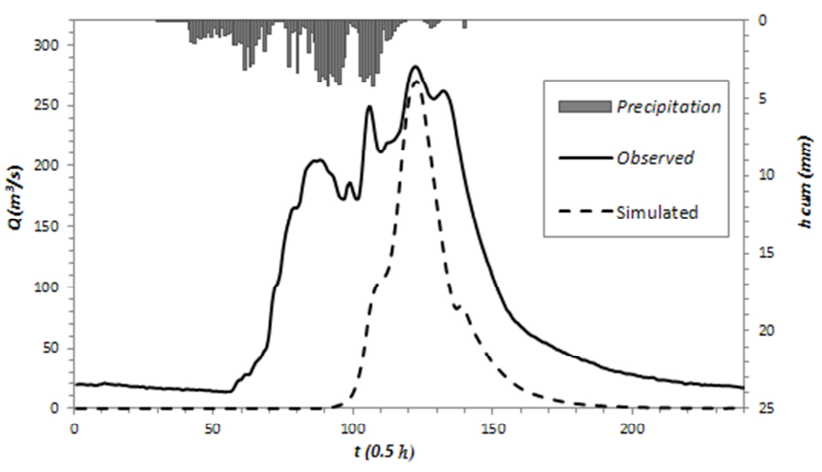

Fig. 4. Calibration and validation of the AMCIII class hydrologic model for the Mignone River basin on the basis of the observed hydrographs at the "Aurelia" gauge station in December 2008 with radar data.

\subsubsection{Utility-entropy approach}

Given the measure of risk of Eq. (9), it is possible to evaluate rainfall thresholds as follows. Given a $V_{\mathrm{T}}$ value, let $\Theta$ be the space of possible state of nature, $A$ the space of action and $X$ the space of consequences of associations between actions and state of nature. Hence, $\Theta_{i}=\left\{\theta_{1}, \theta_{2}\right\}$ has two dimensions where $\theta_{1}$ corresponds to the critical discharge being surpassed, and $\theta_{2}$ corresponds it not being surpassed. $A=\left\{a_{1}, a_{2},\right\}$ has two dimensions where $a_{1}$ corresponds to issuing an alarm when the rainfall threshold is surpassed, and $a_{2}$ corresponds to issuing an alarm when the rainfall threshold is not surpassed. Finally, space $X=X(a, \theta)$, defined in the space $A \times \Theta$, has as components $x_{11}$ (correctly issued alarm), $x_{12}$ (missed alarm), $x_{21}$ (false alarm), and $x_{22}$ (not event, no alarm).

The conditional entropy is defined as:

$H(x \mid y)=\int_{-\infty}^{+\infty} f(x \mid y) \log _{2} f(x \mid y) d x$. 
Table 4. Threshold values evaluated by each method for the Mignone river basin.

\begin{tabular}{|c|c|c|c|c|c|c|}
\hline \multirow[b]{2}{*}{ Method } & \multirow[b]{2}{*}{$\begin{array}{r}\text { AMC } \\
\text { class }\end{array}$} & \multirow[b]{2}{*}{$\begin{array}{l}\text { Duration } \\
\text { (h) }\end{array}$} & \multicolumn{4}{|c|}{$\mathrm{V}_{\mathrm{T}}(\mathrm{mm})$} \\
\hline & & & 3 & 6 & 12 & 24 \\
\hline \multirow{9}{*}{ Bayesian } & \multirow{3}{*}{ I } & "real" case & 20.09 & 21.41 & 25.71 & 34.94 \\
\hline & & "prone" case & 20.02 & 21.01 & 25.02 & 33.05 \\
\hline & & "averse" case & 20.82 & 21.82 & 26.41 & 36.83 \\
\hline & \multirow{3}{*}{ II } & "real" case & 18.27 & 19.28 & 20.54 & 24.94 \\
\hline & & "prone" case & 18.01 & 19.01 & 20.01 & 23.83 \\
\hline & & "averse" case & 18.55 & 19.55 & 21.09 & 26.05 \\
\hline & \multirow{3}{*}{ III } & "real" case & 16.27 & 17.28 & 19.99 & 22.97 \\
\hline & & "prone" case & 16.01 & 17.01 & 19.80 & 22.02 \\
\hline & & "averse" case & 16.55 & 17.55 & 20.18 & 23.92 \\
\hline \multirow{9}{*}{$\begin{array}{l}\text { Utility- } \\
\text { Entropy } \\
(\lambda=0.5)\end{array}$} & \multirow{3}{*}{ I } & "real" case & 21.11 & 21.72 & 26.18 & 36.61 \\
\hline & & "prone" case & 20.04 & 21.02 & 25.03 & 33.09 \\
\hline & & "averse" case & 21.40 & 22.29 & 27.15 & 39.62 \\
\hline & \multirow{3}{*}{ II } & "real" case & 18.28 & 19.28 & 20.93 & 25.92 \\
\hline & & "prone" case & 18.03 & 19.01 & 20.02 & 23.85 \\
\hline & & "averse" case & 18.91 & 19.86 & 21.70 & 27.68 \\
\hline & \multirow{3}{*}{ III } & "real" case & 16.49 & 17.28 & 20.14 & 23.81 \\
\hline & & "prone" case & 16.03 & 17.01 & 19.81 & 22.05 \\
\hline & & "averse" case & 16.90 & 17.55 & 20.42 & 25.31 \\
\hline \multirow{3}{*}{$\begin{array}{l}\text { Entropy } \\
(\lambda=1)\end{array}$} & I & & 22.88 & 23.54 & 29.12 & 47.00 \\
\hline & II & & 19.89 & 20.69 & 23.35 & 32.00 \\
\hline & III & & 17.85 & 18.66 & 21.07 & 29.00 \\
\hline \multirow{4}{*}{$\begin{array}{l}\text { Model } \\
\text { Radar }\end{array}$} & \multirow{4}{*}{ III } & Hyeto 1 & 32.50 & 33.00 & 35.50 & 42.50 \\
\hline & & Hyeto 2 & 32.20 & 32.40 & 33.50 & 36.20 \\
\hline & & Hyeto 3 & 32.50 & 33.20 & 36.50 & 44.50 \\
\hline & & Hyeto 4 & 32.30 & 32.80 & 34.80 & 40.00 \\
\hline
\end{tabular}

In the rainfall threshold case it is:

$H_{a}(\vartheta \mid v)=H(q \mid v)=-\int_{-\infty}^{+\infty} \frac{f(q, v)}{f(v)} \log _{2}\left(\frac{f(q, v)}{f(v)}\right) d q$

where $H(q \mid v)$ can assume:

$H\left(q \mid v>V_{\mathrm{T}}\right)=-\int_{-\infty}^{+\infty} \frac{f(q, v)}{f\left(v>V_{\mathrm{T}}\right)} \log _{2}\left(\frac{f(q, v)}{f\left(v>V_{\mathrm{T}}\right)}\right) d q$

or

$H\left(q \mid v<V_{\mathrm{T}}\right)=-\int_{-\infty}^{+\infty} \frac{f(q, v)}{f\left(v<V_{\mathrm{T}}\right)} \log _{2}\left(\frac{f(q, v)}{f\left(v<V_{\mathrm{T}}\right)}\right) d q$

The parameter $\lambda$ can be varied in order to adjust the weights of the objective and subjective components. Let us consider two cases. A total of nine threshold values are obtained in the case of a perfect tradeoff between objective and subjective components $(\lambda=0.5)$ (Table 4$)$. In the second case, the tradeoff coefficient $\lambda$ is equal to 1 ; therefore, in Eq. (9) only the component related to entropy is considered. The threshold values obtained are a minimization of Eq. (15), regardless of the perception of the decision-maker. In this case a single curve of the threshold values for each AMC condition is obtained (Fig. 7).

\subsubsection{Radar based simulation approach}

The inverse hydrological problem was solved by identifying the configuration of the rainfall field that leads to exceeding the critical discharge (see Sect. 3.1). Table 4 summarises rainfall threshold values corresponding to each rainfall configuration, for the AMCIII soil condition. 

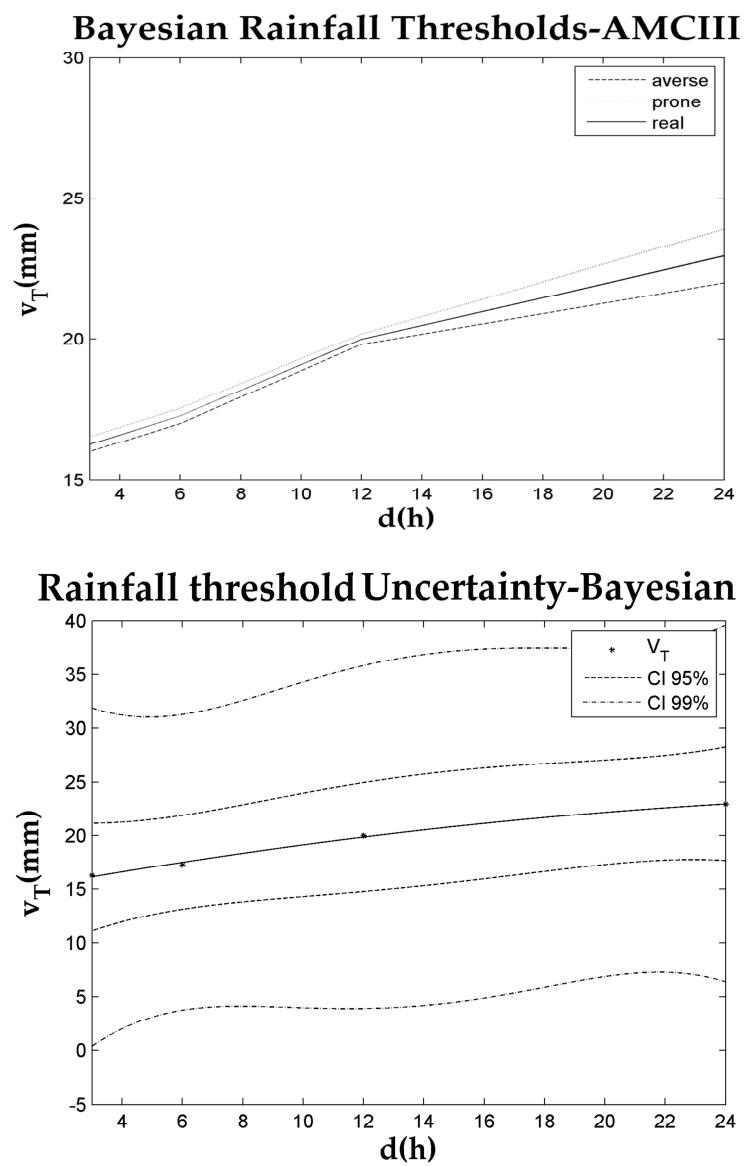

Fig. 5. Threshold values evaluated by Bayesian approach for the Mignone River basin: "real" case (solid line), "prone" case (dotted line) and "averse" case (dashed line) for the AMCIII soil condition (upper panel) and uncertainty associated with "real" case threshold (lower panel).

\section{Reliability evaluation}

To estimate the reliability of rainfall thresholds, it is necessary to investigate the presence of any missed or false alarms. A missed alarm (MA) is defined as when the flood event exceeds the critical reference discharge in the critical crosssection, but the recorded precipitation does not exceed the rainfall threshold. A false alarm (FA) is when the rainfall threshold is surpassed, but the observed discharge is lower than the critical reference discharge.

Obviously, FAs and especially MAs, invalidate the reliability of rainfall thresholds as a warning tool. A possible way to assess the performance of the proposed method is to use a two-by-two contingency table (Mason and Graham, 1999). The table is structured as follows: the $n$ observations are divided in Event $E$ (critical discharge surpassed) and Not Event $E^{\prime}$ (critical discharge not surpassed). If an event occurred and a warning was issued the outcome is a hit (with $h$ being the total number of hits); if an event did not occur but
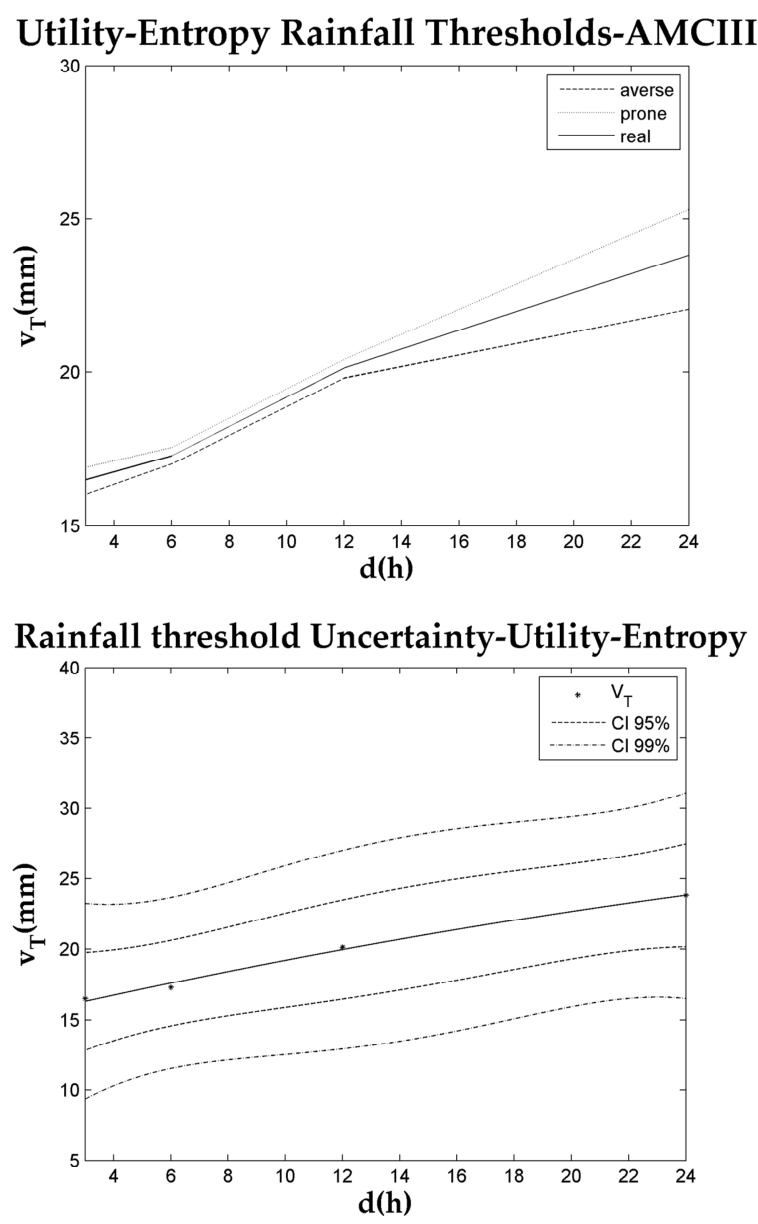

Fig. 6. Threshold values evaluated via the utility-entropy measure of risk approaches $(\lambda=0.5)$ for the Mignone River basin: "real" case (solid line), "prone" case (dotted line) and "averse" case (dashed line) for AMCIII soil condition (upper panel) and uncertainty associated with "real" case AMCIII threshold (lower panel).

a warning was issued the outcome is a false alarm (with $f$ being the total number of false alarms); if an event occurred but a warning was not issued the outcome is a missed alarm (with $m$ being the total number of misses); if an event did not occur and a warning was not issued the outcome is a correct rejection (with $c$ being the total number if correct rejections). The total number of warnings is $w$, the total of no warnings $w^{\prime}$, the total number of events $e$ and not-events $e^{\prime}$.

The performance can be evaluated in terms of the hit rate (proportion of events for which a warning is correctly provided) and false alarm rate (proportion of not events for which a warning is incorrectly provided), defined as follows (Mason, 1982):

hit rate $=\frac{h}{h+m}=\frac{h}{e}=p(w \mid E)$ 

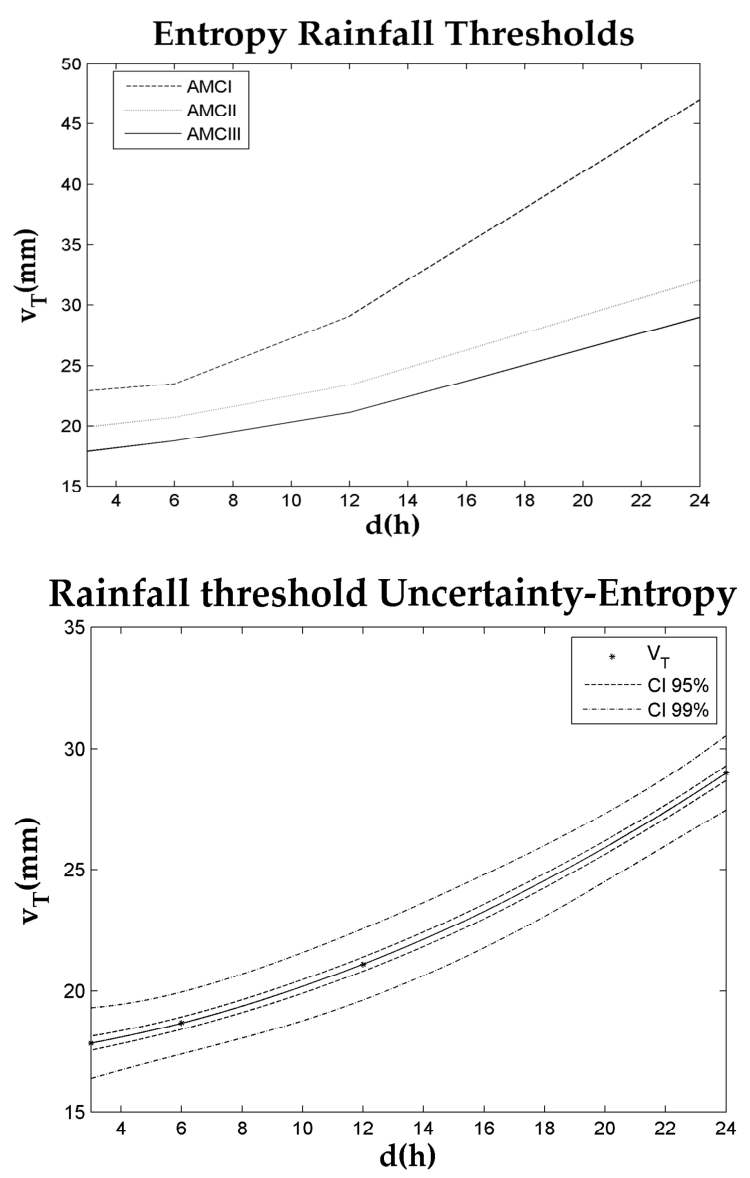

Fig. 7. Threshold values evaluated via the utility-entropy measure of risk approach $(\lambda=1)$ for the Mignone River basin, for all the AMC conditions: AMCI (dashed line), AMCII (dotted line) and AMCIII (solid line) in the upper panel. Uncertainty associated with the AMCIII threshold is in the lower panel.

and

false alarm rate $=\frac{f}{f+c}=\frac{f}{e^{\prime}}=p\left(w \mid E^{\prime}\right)$

The hit rate can be considered as the probability of detection and provides an estimate of the probability that an event will be forewarned, while the false-alarm rate can be considered as the probability that a warning will be incorrectly issued. For a warning system with no skills, warning and events are independent, so that:

$p(w \mid E)=p\left(w \mid E^{\prime}\right)=p(w)$.

When a threshold-based forecasting system has some skill, the hit rate exceeds the false-alarm rate. The performance can be measured by (Gandin and Murphy, 1992):

skillscore $=\frac{h}{e}-\frac{f}{e^{\prime}}$

A performance is considered good is when skillscore $>0$.
Table 5. Two-by-two contingency table for assessing the efficiency of rainfall threshold evaluation methodologies.

\begin{tabular}{|c|c|c|c|c|}
\hline Method & Observations & $\begin{array}{r}\text { Alarms } \\
W\end{array}$ & $\begin{array}{r}\text { Not alarms } \\
W^{\prime}\end{array}$ & Total \\
\hline \multirow{3}{*}{$\begin{array}{l}\text { Bayesian } \\
\text { Real case }\end{array}$} & Event $E$ & 19 & 6 & 25 \\
\hline & Not event $E^{\prime}$ & 13 & 9 & 22 \\
\hline & Total & 32 & 15 & 47 \\
\hline \multirow{3}{*}{$\begin{array}{l}\text { Utility- } \\
\text { Entropy } \\
(\lambda=0.5)\end{array}$} & Event $E$ & 24 & 1 & 25 \\
\hline & Not event $E^{\prime}$ & 12 & 10 & 22 \\
\hline & Total & 36 & 11 & 47 \\
\hline \multirow{3}{*}{$\begin{array}{l}\text { Entropy } \\
(\lambda=1)\end{array}$} & Event $E$ & 23 & 2 & 25 \\
\hline & Not event $E^{\prime}$ & 7 & 15 & 22 \\
\hline & Total & 30 & 17 & 47 \\
\hline \multirow{3}{*}{ Radar } & Event $E$ & 10 & 1 & 11 \\
\hline & Not event $E^{\prime}$ & 4 & 4 & 8 \\
\hline & Total & 14 & 5 & 19 \\
\hline \multirow{3}{*}{ Raingauge } & Event $E$ & 20 & 5 & 25 \\
\hline & Not event $E^{\prime}$ & 8 & 14 & 22 \\
\hline & Total & 28 & 19 & 47 \\
\hline
\end{tabular}

The contingency tables corresponding to the Bayesian approach (real case), utility-entropy measure of risk $(\lambda=0.5)$, utility-entropy measure of risk $(\lambda=1)$, hydrologic simulation based on radar data (AMCIII condition) and raingauge data (all AMC conditions) are reported in Table 5.

The reliability of the estimated rainfall thresholds is evaluated performing a back analysis on the flood events of the period 1998-2010. The last two years of the dataset were not used in the calibration phase, but only in the validation stage.

Even if the numerical values of rainfall thresholds are quite similar, the analysis of the performance of each methodology offers interesting results.

The best performance in terms of hits is for the utilityentropy approach measure of risk $(\lambda=0.5)$, followed by the utility-entropy measure of risk $(\lambda=1)$.

The methods based on hydrological simulation performed quite well, especially using radar data (high number of hits, only one MA). The presence of false alarms seems to be related to an overestimation of the cumulative rainfall obtained from radar data. However, the results of efficiency based on radar measures are influenced by the limited availability of data (only the AMCIII conditions were examined).

The worst performance is obtained with the Bayesian approach. In fact, the number of hits and false alarms is comparable, and the number of missed alarms is high. This is probably influenced by the utility function parameters that need a calibration on the examined river basin.

The previous results are synthetically summarized by the skill scores (Table 6). All the methodologies have a positive skill score, ranging from 0.17 (Bayesian method) to 
Table 6. Reliability summary analysis: values of hit rate, false alarm rate and skill score are presented in order to compare the methodologies.

\begin{tabular}{lccccc}
\hline & Bayesian & $\begin{array}{c}\text { UE-Risk } \\
(\lambda=0.5)\end{array}$ & $\begin{array}{c}\text { Entropy } \\
(\lambda=1)\end{array}$ & $\begin{array}{c}\text { Hydrologic } \\
\text { simulation } \\
\text { (radar data) }\end{array}$ & $\begin{array}{c}\text { Hydrologic } \\
\text { simulation } \\
\text { (rain gauge) }\end{array}$ \\
\hline Hit rate & 0.76 & 0.96 & 0.92 & 0.91 & 0.80 \\
False alarm rate & 0.59 & 0.55 & 0.32 & 0.50 & 0.36 \\
skill score & 0.17 & 0.41 & 0.60 & 0.41 & 0.44 \\
\hline
\end{tabular}
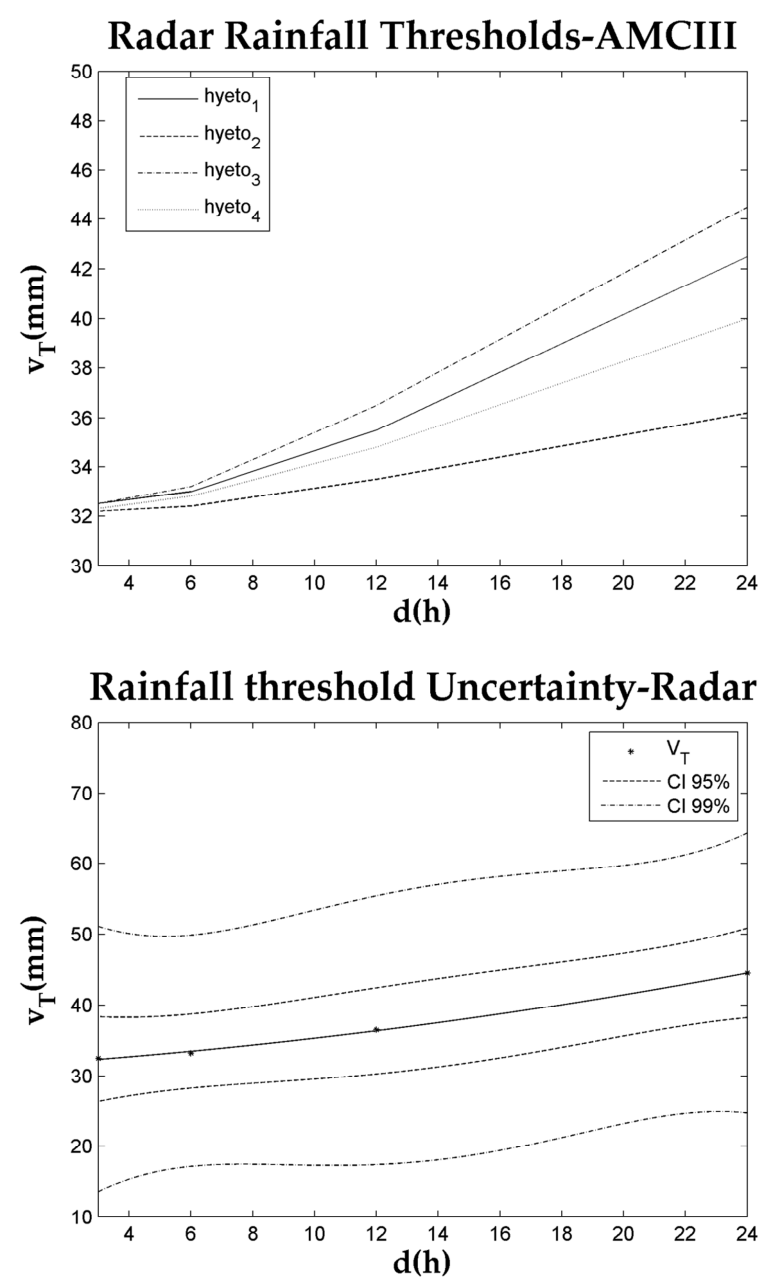

Fig. 8. Threshold values evaluated by hydrological model calibrated with radar data for AMCIII soil conditions (upper panel) and uncertainty associated with hyeto 1 threshold for the Mignone River basin (lower panel).

0.60 (entropy approach). It is interesting to highlight that the thresholds evaluated via hydrological simulation (rain gauge data) offer the same skill score as the utility-entropy approach measure of risk.
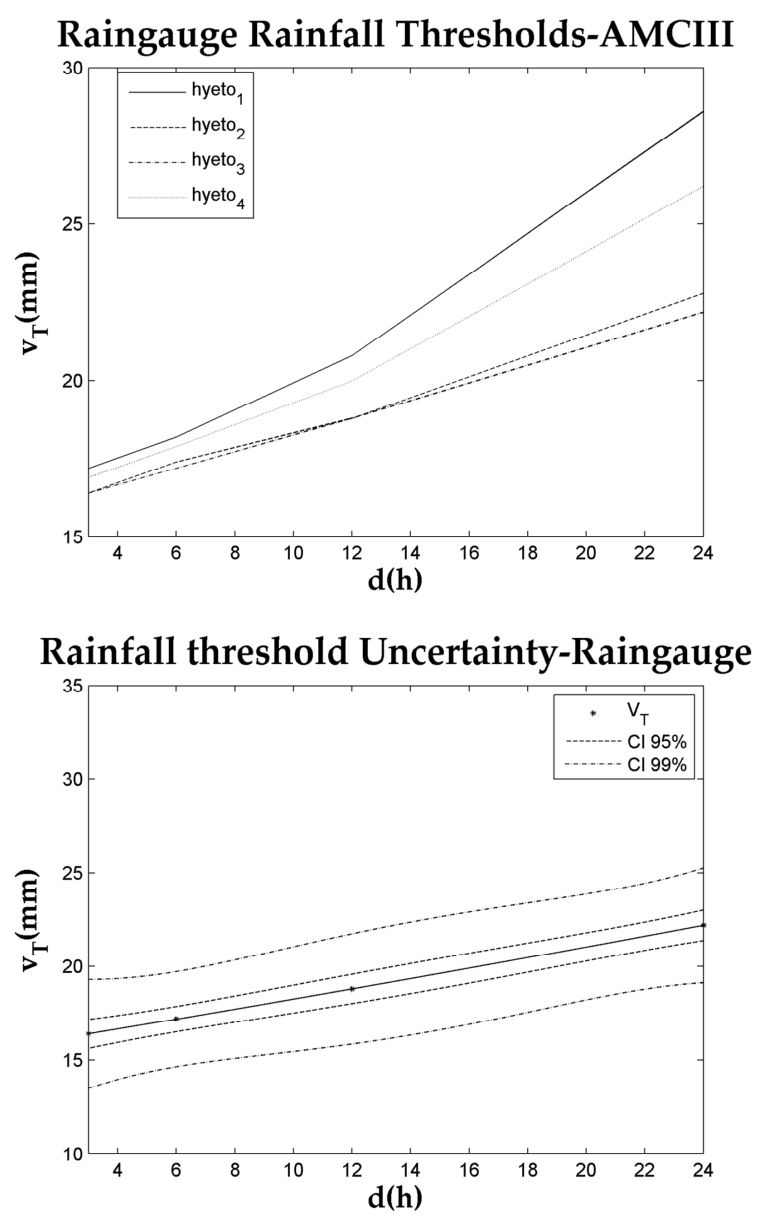

Fig. 9. Threshold values evaluated by a hydrological model calibrated with raingauge data for AMCIII soil conditions (upper panel) and uncertainty associated with hyeto1 threshold for the Mignone River basin (lower panel).

The skill scores are therefore encouraging for the efficiency of the proposed methodologies as flood warning tools in a future operative framework. However, a wider data set is need to achieve more accurate reliability evaluation of each examined methodology. 


\section{Discussion and conclusions}

This work presents a simplified model for the management of alert systems used for flood events. Values in excess of a threshold trigger prevention actions and an emergency system alert. The definition of threshold values is obtained via a probabilistic approach and by a simulation model based on weather radar data.

Two probabilistic methodologies were compared by back analysis. In the Bayesian approach proposed by Martina et al. (2006), rainfall threshold values depend on the decisionmaker's perception of risk. Using the utility-entropy risk function approach, a combination of objective (represented by the entropy function) and subjective (represented by the expected value of the utility function) components permits the evaluation of rainfall threshold values, weighing the subjective perception of the stakeholder by using the opportune value of the trade-off coefficient. By imposing a balance parameter $\lambda=1$, the subjective perception of the decisionmaker does not affect the determination of threshold values, which are obtained exclusively by minimizing the information entropy. This methodology is thus more objective and offers the best performance in terms of skill score. Thresholds obtained by hydrological simulation based on weather radar data perform quite well, but there is still a need for more data in order to achieve more accurate performance testing.

A question of growing importance is the study of uncertainty of estimated rainfall threshold values (Ntelekos et al., 2006; Villarini et al., 2010b). In fact, every proposed approach to rainfall threshold evaluation is affected by various sources of uncertainty. For example, considering the hydrological model, the uncertainties related to the inputs (raingauge data, radar data, discharge data evaluated with rating curve, basin characterization) influenced the outputs (calibrated basin parameters and simulated discharges). In this work only an overall evaluation of uncertainty is performed. As shown in the lower panel of Figs. 5-9, the confidence intervals (95\% and $99 \%$ ) of the proposed rainfall thresholds were evaluated. Clearly, the greater the source of uncertainty, the wider the confidence intervals.

Future studies should investigate more carefully the influence of each component on rainfall threshold values. Associating an uncertainty value to rainfall thresholds allows the users to make optimal decisions about issuing or not issuing flood warnings.

Acknowledgements. The authors would like to thank Ufficio Idrografico e Mareografico of Lazio Region for providing hydrometric and pluviometric data and the Institute of Atmospheric Sciences and Climate of the National Research Council for providing radar data. In addition, the authors would like to thank the reviewers for their useful comments, which helped to improve the manuscript.

Edited by: G. Boni

Reviewed by: two anonymous referees

\section{References}

Annunziati, A., Focardi, A., Focardi, P., Martello, S., and Vannocci, P.: Analysis of the rainfall thresholds that induced debris flows in the area of Apuan Alps - Tuscany, Italy, Plinius Conference '99: Mediterranean Storms, Ed. Bios., 485-493, 1999.

Bloeschl, G.: Rainfall-runoff modelling of ungauged catchments. Article 133 in: Encyclopedia of Hydrological Sciences, M. G. Anderson (Managing Editor), J. Wiley \& Sons, Chichester, 2061-2080, 2005.

Brath, A., Castellarin, A., Franchini, M., and Galeati, G.: Estimating the index flood using indirect methods, Hydrolog. Sci. J., 46(3), 399-418, 2001.

Carpenter, T. M., Sperfslage J. A., Georgakakos K. P., Sweeney, T., and Fread, D. L.: National threshold runoff estimation utilizing GIS in support of operational flash flood warning systems, J. Hydrol., 224, 21-44, 1999.

Ciach, G. J., Krajewski, W. F., and Villarini, G.: Product-errordriven uncertainty model for probabilistic quantitative precipitation estimation with NEXRAD data, J. Hydrometeorol., 8(5), 1325-1347, 2007.

Crosta, G. B. and Frattini, P.: Rainfall thresholds for soil slip and debris flow triggering, Proceedings of the EGS 2nd Plinius Conference on Mediterranean Storms, Ed. Bios, 2000.

Dalrymple, T.: Flood frequency analyses, Water Supply Paper 1543-A, US Geol. Survey, Reston, Virginia, USA, 1960.

FLOODsite - Borga, M.: Realtime Guidance for flash flood risk management, available at: http//www.floodsite.net (last access: May 2009), 2008.

Gandin, L. S. and Murphy, A. H.: Equitable skill scores for categorical forecasts, Mon. Weather Rev., 120, 361-370, 1992.

Georgakakos, K. P.: Real time prediction for flood warning and management, US-Italy Research Workshop on the Hydrometeorology, Impacts, and Management of Extreme Floods Perugia (Italy), November 1995, 1995.

Georgakakos, K. P.: Analytical results for operational flash flood guidance, J. Hydrol., 317, 81-103, 2006.

Germann, U., Galli, G., Boscacci, M., and Bolliger, M.: Radar precipitation measurement in a mountainous region, Q. J. Roy. Meteor. Soc., 132(618), 1669-1692, 2006.

Giulianelli, M., Miserocchi, F., Napolitano, F., and Russo, F.: Influence of space-time rainfall variability on urban runoff, Proceeding of the 17th IASTED International Conference Modelling and Simulation, Montreal, QC, Canada, 546-551, 2006.

Habib, E., Ciach, G. J., and Krajewski, W. F.: A method for filtering out raingauge representativeness errors from the verification distributions of radar and raingauge rainfall, Adv. Water Resour., 27(7), 967-980, 2004.

Kelly, K. S. and Krzysztofowicz, R.: A bivariate meta-Gaussian density for use in hydrology, Stoch. Hydrol. Hydraul., 11, 1731, 1997.

Krajewski, W. F. and Smith, J. A.: Radar hydrology: rainfall estimation, Adv. Water. Resour., 25(8-12), 1387-1394, 2002.

Kull, D. W. and Feldman, A. D.: Evolution of Clark's unit graph method to spatially distributed runoff, J. Hydrol. Eng., 3(1), 919, 1998.

Lombardo, F., Napolitano, F., Russo, F., Scialanga, G., Baldini, L., and Gorgucci, E.: Rainfall estimation and ground clutter rejection with dual polarization weather radar, Adv. Geosci., 7, 127130, doi:10.5194/adgeo-7-127-2006, 2006a. 
Lombardo, F., Napolitano, F., and Russo, F.: On the use of radar reflectivity for estimation of the areal reduction factor, Nat. Hazards Earth Syst. Sci., 6, 377-386, doi:10.5194/nhess-6-3772006, 2006b.

Lombardo, F., Montesarchio, V., Napolitano, F., Russo, F., and Volpi, E.: Operational applications of radar rainfall data in urban hydrology, IAHS-AISH Publication, 327, 258-266, 2009.

Mancini, M., Mazzetti, P., Nativi, S., Rabuffetti, D., Ravazzani, G., Amadio, P., and Rosso, R.: Definizione di soglie pluviometriche di piena per la realizzazione di un sistema di allertamento in tempo reale per il bacino dell' Arno a monte di Firenze, Proc. XXVII Convegno di idraulica e Costruzione Idrauliche, 2, 497505, Italy, 2002.

Martina, M. L. V., Todini, E., and Libralon, A.: A Bayesian decision approach to rainfall thresholds based flood warning, Hydrol. Earth Syst. Sci., 10, 413-426, doi:10.5194/hess-10-413-2006, 2006.

Mason, S. J.: A model for assessment of weather forecasts, Aust. Meteorol. Mag., 30, 291-303, 1982.

Mason, S. J. and Graham, N. E.: Conditional probabilities, relative operating characteristics and relative operating levels, Weather Forecast., 14, 713-725, 1999.

Mogil, H. M., Monro, J. C., and Groper, H. S.: NWS's flash flood warning and disaster preparedness programs, B. Am. Meteorol. Soc., 59, 690-699, 1978.

Montesarchio, V., Lombardo, F., and Napolitano, F.: Rainfall thresholds and flood warning: an operative case study, Nat. Hazards Earth Syst. Sci., 9, 135-144, doi:10.5194/nhess-9-1352009, 2009.

Neary, D. G. and Swift, L. W.: Rainfall thresholds for triggering a debris flow avalanching event in the southern Appalachian Mountains, Rew. Eng. Geol., 7, 81-95, 1987.

Norbiato, D., Borga, M., Degli Esposti, S., Gaume, E. and Anquetin, S.: Flash flood warning based on rainfall thresholds and soil moisture conditions: An assessment for gauged and ungauged basins, J. Hydrol., 362, 274-290, 2008.

Ntelekos, A. A., Georgakakos, K. P., and Krajewski, W. F.: On the uncertainties of flash flood guidance: toward probabilistic forecasting of flash floods, J. Hydrometeorol., 7, 896-915, 2006.
Papoulis, A.: Probability, random variables and stochastic processes, 3rd Edn., McGraw-Hill, New York, 1991.

Peters, J. C. and Easton, D. J.: Runoff simulation using radar rainfall data, Water Resour. Bull., 32(3), 753-760, 1996.

Pilgrim, D. H. and Cordery, I.: Flood runoff, in: Handbook of hydrology, edited by: Maidment, D. R., McGraw-Hill, New York, NY, USA, 9, 1-42, 1993.

Rosso, R.: Manuale di protezione idraulica del territorio, Cusl, Milano, 2002.

Russo, F., Napolitano, F., and Gorgucci, E.: Rainfall monitoring systems over an urban area: the city of Rome, Hydrol. Process., 19(4), 1007-1019, 2005.

Russo, F., Lombardo, F., Napolitano, F., and Gorgucci, E.: Rainfall stochastic modelling for runoff forecasting, Phys. Chem. Earth, 31(18), 1251-1261, 2006.

Soil Conservation Service. Urban hydrology for small watersheds, Technical Release 55, US Department of Agriculture, Springfield, VA, 1986.

Soil Conservation Service. National engineering handbook, Cross section 4: Hydrology, US Department of Agriculture, Springfield, VA, 1971.

Villarini, G., Lang, J. B., Lombardo, F., Napolitano, F., Russo, F., and Krajewski, W. F.: Impact of different regression frameworks on the estimation of the scaling properties of radar rainfall, Atmos. Res., 86(3-4), 340-349, 2007.

Villarini, G. and Krajewski, W. F.: Review of the different sources of uncertainty in single polarization radar-based estimates of rainfall, Surv. Geophys., 31(1), 107-129, doi:10.1007/s10712009-9079-x, 2010a.

Villarini, G., Krajewski, W. F., Ntelekos, A. A., Georgakakos, K. P., and Smith, J. A.: Towards probabilistic forecasting of flash floods: the combined effects of uncertainty in radar-rainfall and flash flood guidance, J. Hydrol., 394, 275-284, 2010 b.

Wilson, J. W. and Brandes, E. A.: Radar measurement of rainfall a summary, B. Am. Meteorol. Soc., 60(6), 1048-1058, 1979.

Yang, J. and Qiu, W.: A measure of risk and a decision-making model based on expected utility and entropy, Eur. J. Oper. Res., 164, 792-799, 2005. 